\title{
EL JOROBADO EN LA LITERATURA LATINOAMERICANA: ESCARNIO SOCIAL Y FRACASO PERFORMATIVO DE LA VOZ DEL MONSTRUO MORAL EN “EL JOROBADITO”, DE ROBERTO ARTL
}

Dorde Cuvardic García

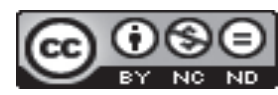

Esta obra está bajo una licencia Creative Commons Reconocimiento-No Comercial-Sin Obra Derivada 



\title{
EL JOROBADO EN LA LITERATURA LATINOAMERICANA: ESCARNIO SOCIAL Y FRACASO PERFORMATIVO DE LA VOZ DEL MONSTRUO MORAL EN “EL JOROBADITO”, DE ROBERTO ARTL
}

\author{
THE HUNCHBACK IN LATIN AMERICAN LITERATURE: SOCIAL \\ MOCKERY AND PERFORMATIVE FAILURE FROM THE VOICE OF \\ THE MORAL MONSTER IN “EL JOROBADITO” BY ROBERTO ARTL
}

\section{Dorde Cuvardic García}

\begin{abstract}
RESUMEN
Hasta ahora, los análisis que se han realizado de "El jorobadito", de Roberto Artl se han centrado en la figura del narrador, en su actitud ante el matrimonio y en las difíciles relaciones que sostiene con su futura suegra y la mediocre sociedad pequeñoburguesa. Cuando se han ocupado de la figura del jorobado, han destacado, sobre todo, su condición de doble del narrador, proyección que materializa la conciencia reprimida del protagonista. El objetivo del presente artículo, en cambio, se dirige a explicar las posibles funciones que reviste el jorobado en este cuento y en la cultura occidental: monstruo moral, objeto de escarnio, sujeto que atrae la suerte. En todo caso, objeto de escarnio social, Rigoletto -de onomástica relevante para nuestro análisis- es un 'chivo expiatorio' sobre el que se descargan las culpas y deseos reprimidos de la sociedad 'bienpensante'. Además, queremos demostrar que este personaje, que tiene voz propia, busca modificar -sin éxito- el comportamiento de la sociedad hacia el monstruo moral del jorobado, entendida como figura genérica. La fuerza performativa de su palabra es nula y recibe la sanción negativa de la sociedad, la muerte, a través del asesinato del narrador. Palabras clave: jorobado, literatura argentina, escarnio, monstruo moral, otredad.
\end{abstract}

\begin{abstract}
So far, the analyses that have been conducted about "El Jorobadito" by Roberto Artl have been focused on the narrator, on his attitude toward marriage and the difficult relation he maintains with his future mother-in-law and the mediocre and small bourgeois society. When they have dealt with the figure of the hunchback, they have highlighted, above all, his condition as a double narrator, a projection that materializes the repressed consciousness of the protagonist. The purpose of this article, however, is directed toward explaining the possible functions that the hunchback covers in this story and in Western culture: moral monster, object of mockery, individual that attracts luck. In any case, the subject of social ridicule, Rigoletto -of relevant onomastic for our analysis - is a "scapegoat" over whom the guilt and repressed desires of the 'right-thinking' society are vent. Furthermore, we want to demonstrate that this character has his own voice, unsuccessfully seeks to modify society's behavior towards the hunchback as moral monster, understood as a generic figure. The performative force of his word is null (invalid) and receives the negative sanction of society, death, through the murder of the narrator. Key words: hunchback, Argentina literature, mockery, moral monster, otherness.
\end{abstract}

Dr. Dorde Cuvardic García. Universidad de Costa Rica. Profesor de la Escuela de Filología, Lingüística y Literatura. Costa Rica.

Correo electrónico: dcuvardic@yahoo.es

Recepción: 31- 12- 2014

Aceptación: 19- 06- 2015 
La deformidad física forma parte de la llamada Otredad dentro de la propia cultura, como también ocurre con el hirsutismo o el idiotismo, frente a la llamada Otredad ajena (configurada esta última a partir del contacto, muchas veces conflictivo, con otras culturas).

La deformidad -como origen de la experiencia emotiva del temor o del terror- es un tema de imitación legítimo en la literatura desde que Aristóteles, en el Capítulo IV de su Poética, declarase que la mímesis, incluso de objetos desagradables, supone una placentera fuente de conocimiento. Ilustra esta afirmación desde las artes visuales. Sobre el placer que provocan connaturalmente las imitaciones, precisa que ante cosas vistas directamente con desagrado, en cambio, "sus imágenes, realizadas con máxima exactitud, las contemplamos gozosos, como ocurre, por ejemplo, con las formas de los animales más repulsivos o con cadáveres." (Aristóteles, 1994, p. 39). Más allá de encontrar en esta declaración un germen de la estética occidental de lo grotesco, nos interesa señalar que el Estagirita afirma que incluso los objetos de imitación (los temas de representación) feos o repulsivos también provocan un placer que actualmente llamaríamos estético y que pueden ser fuente de conocimiento, cuando el espectador reconoce en ellos su condición de imitaciones de referentes reales.

Un hito en el reconocimiento de la estética de lo grotesco en la teoría literaria lo proporciona el "Prólogo" al Cromwell (1827), de Victor Hugo. Además de realizar un rápido recorrido en este paratexto por sus manifestaciones paradigmáticas en el Occidente europeo, vincula su auge con el desarrollo de la literatura moderna (que actualmente llamaríamos romántica), caracterizada por la combinación de lo sublime y lo grotesco, por la armonía de los contrarios; según Victor Hugo, lo grotesco solo puede surgir y tener caldo de cultivo en una cultura cristiana, perfilada a partir de la oposición y síntesis de lo material y lo espiritual. En particular, en el Romanticismo, que favorece la estética de lo grotesco, se da una eclosión de personajes jorobados, entre ellos Nuestra Señora de París (El jorobado de Notre-Dame), 1831, del mencionado autor francés. Cuando el narrador de esta última novela describe por vez primera al jorobado, lo hace en el marco de un retrato que cosifica parcialmente al sujeto humano (por contrapartida, le confiere la dignidad del valor, la agilidad y el vigor), con la bienvenida que da el pueblo, en época de Carnaval, al papá de los locos:

\footnotetext{
toda su persona era una mueca. Una enorme cabeza erizada de pelos rojizos; entre los hombros, una joroba enorme cuya contrapartida se dejaba adivinar por delante; una organización de muslos y piernas tan extrañamente combinada que sólo se tocaban en las rodillas y que, vistos de frente, parecían dos hojas de hoz que se juntasen por los mangos; unos pies enormes, unas manos monstruosas y, a pesar de todas aquellas deformidades, un indefinido aspecto de vigor, de agilidad y de valor. (Hugo, 1980, p. 62)
}

Por lo general, la joroba queda integrada en las representaciones literarias junto a otras marcas de la monstruosidad física: queda acompañada por la cojera, el cabello pelirrojo y el enanismo. Además, en ocasiones, como ocurre en la novela de Victor Hugo, la parte, por sinécdoque, sustituye a la totalidad: en el marco de la prosopografía, un atributo, la joroba, identifica y nombra al personaje.

En el siglo XIX queda tipificado el grado de Otredad que tiene el jorobado frente a la 'normalidad corporal', desde la mirada disciplinaria de la sociedad. Violenta las leyes 'naturales' y jurídicas: "Es, en un doble registro, infracción a las leyes en su misma existencia. El campo de aparición del monstruo [...] es un dominio al que puede calificarse de jurídico biológico." (Foucault, 2000, p. 61). Desde este punto de vista, el monstruo se revela como una construcción discursiva jurídico-biológica tan inestable, que termina por exhibir el carácter autoritario y disciplinario de la ley que lo ha 'creado'. La noción de monstruosidad permite 
denunciar el autoritarismo de la sociedad en la que ha surgido. En palabras de Foucault (2000, p. 62), "lo que constituye la fuerza y la capacidad de inquietud del monstruo es que, a la vez que viola la ley, la deja sin voz. Pesca en la trampa a la ley que está infringiendo”. Lo mismo ocurre con todo escarnio e insulto legitimado por la sociedad: termina por hacer crisis, como sucede con el término queer. La literatura, en ocasiones, al dar voz al ser monstruoso, exhibe como arbitrarias las pretensiones sancionadoras de la sociedad hegemónica. Así, por ejemplo, algunos textos otorgan voz al jorobado, que denuncia el rechazo recibido por la sociedad y defiende con dignidad su humanidad. Así lo hace el sujeto protagonista en Ricardo III (1591-1592), de William Shakespeare. El propio monarca, en la Escena I, caracteriza su monstruosidad -e implícitamente, el castigo sancionador de la sociedad-, por el simple hecho de alejarse del canon oficial de la Belleza física: "yo, contrahecho y sin la majestuosa gentileza para pavonearme ante una ninfa de libertina desenvoltura; yo, privado de la bella proporción, desprovisto de todo encanto por la pérfida naturaleza; deforme, mal fraguado, enviado antes de tiempo a este latente mundo" (Shakespeare, 1998, pp. 31-32). Como el propio monarca explica, no se cumplen en su caso, como ocurre con todo jorobado, dos de los atributos de la Belleza sensible: la simetría y la proporción.

En la sociedad occidental, el jorobado asume connotaciones principalmente negativas. En primer lugar, en la figura cultural del jorobado se da la asociación típica entre deformidad física y moral. Es objeto de una lectura o interpretación de carácter fisiognómico: las marcas visibles físicas, desviadas del promedio, se constituyen en metonimia de una moral alejada del bien. Se convierte en fuente de temor.

En segundo lugar, la deformidad física, aplicada al caso genérico del jorobado, cuando no es acompañada del mencionado temor moral, es considerada ridícula y, como tal, asumida como potencial fuente de escarnio. Desde este punto de vista, el jorobado despierta, simplemente, asco y repulsión. La intención de escarnecer esta deformidad física se produce incluso en el campo literario, en las sátiras producidas al calor de las polémicas entre escritores. Así, por ejemplo, Quevedo se burló, en la letrilla "Sátira de Quevedo contra Corcovilla", de la joroba de Juan Ruíz de Alarcón: “QQuién es muñeca de andrajos,/ y tiene, en forma de zote,/ las pechugas con cogote,/ las costillas con zancajos?" (Quevedo, 1852, xxxi-xxxii). Este ataque fue respondido posteriormente por el dramaturgo mexicano con "Patacoja" (Peña, 2004, p. 66), en alusión a la cojera del escritor español. La joroba también forma parte de la representación icónica del escritor o artista atormentado, en relación conflictiva con su sociedad, como ocurre con el pintor francés Toulouse Lautrec y del poeta italiano Leopardi. Atributo cuyo repudio permite escarnecer socialmente al que lo lleva, puede incorporarse en las representaciones visuales del enemigo político. Como ejemplo de esta última intencionalidad ideológica, el historiador del arte Carlos Reyero (2005, p. 122) nos recuerda que Diego Rivera representó a Hernán Cortés como bizco, jorobado y cojo en el mural La llegada de Hernán Cortés en 1519 (1951, México Palacio Nacional).

En este punto podemos plantear la siguiente pregunta: ¿Qué distingue a la deformidad física como objeto de temor, por una parte, y como objeto de escarnio, por otra? Creo que la respuesta se encuentra en el grado de visibilidad social que tiene su portador: la deformidad física, cuanto más oculta se encuentre, más monstruosa resultará, moralmente hablando. En la estética prerromántica, Burke (1987, p. 45) establece la dicotomía entre los seres monstruosos ocultos o medio ocultos al observador -que, como una idea vaga, oscura e imprecisa, afectan al alma humana, produciendo la afección del terror- frente a los seres monstruosos (es decir, 
deformes) que, vistos o percibidos claramente, son considerados, por contrapartida, ridículos. La deformidad monstruosa de los seres espectrales de los cuadros de Füssli, por ejemplo, es amenazante porque estos seres se encuentran semiocultos: no conocemos sus verdaderas dimensiones, su origen o su potencial fuerza para dañar. En cambio, la deformidad visible y accesible en la cotidianeidad pierde, ante los ojos de la sociedad, esta última potencial fuerza para dañar. La amenaza de un posible poder físico ilimitado se resuelve en carencia, en debilidad, y esta última, cuando es percibida por la sociedad en el sujeto discapacitado, queda convertida en objeto de escarnio. Como ejemplo, podemos ofrecer las reflexiones del narrador del folletín argentino El jorobado (1880), de Eduardo Gutiérrez, dedicado al famoso ladrón Domingo Parodi: "El físico de este pequeño individuo era ridículo hasta el punto de no podérsele mirar sin reír, ya por su enorme joroba, ya por sus piernas cortas y cambadas, como la expresión satírica de su semblante.” (citado por Rodríguez-McGill, 2012, p. 115).

En tercer lugar, la deformidad física puede ser objeto de conmiseración o lástima. En este punto, la representación del jorobado, objeto de temor, se distingue de la imagen de la jorobada. En la literatura del siglo XIX y de inicios del XX es común la figura de la niña jorobadita que despertará la compasión del lector. Un caso proviene del cuento "Nuestra Señora de los Locos", del guatemalteco Rafael Arévalo Martínez, donde el narrador afirma, concisamente: "Mi pobre hermana era una infeliz criatura. Era jorobada" (1958, p. 112). La jorobada es un personaje secundario que amuebla el mundo ficcional de la literatura de esta época. En Fortunata y Jacinta, de Benito Pérez Galdós, el narrador describe el fanatismo de Juan Pablo Rubín por los cafés madrileños, y en el marco de esta descripción se realiza una rápida mención de una cerillera: "Hasta con la jorobadita que vendía en la puerta fósforos y periódicos tenía cierto parentesco espiritual." (Pérez-Galdós, 1994, p. 582). Las taras son comunes en la estética naturalista y abundan en esta escritura, en consecuencia, personajes que el narrador trata con lástima y conmiseración. Un último ejemplo: Minguito, niño jorobado de El cisne de Vilamorta (1885), de Emilia Pardo Bazán.

En cuarto lugar, como sujeto excepcional, y frente a las definiciones previas, al jorobado se le considera portador de la buena suerte. Esta creencia supone una materialización del animismo reprimido por el proceso civilizatorio. Una creencia popular afirma que tocar la joroba del sujeto deforme traerá suerte al que ha realizado esta acción.

¿Qué provoca el relativo auge del jorobado en la cultura occidental desde mediados del siglo XIX hasta el primer tercio del siglo XX? Creo que la respuesta se explica por el hecho de que en este periodo adquirieron auge aquellas formaciones sociales disciplinarias encargadas de tipificar, desde el discurso jurídico-biológico ya mencionado, las distintas deformidades físicas del ser humano, identificadas como marcas de insuficiencia mental o monstruosidad moral. El jorobado es resultado o producto de aquellas disciplinas encargadas, en el siglo XIX, de identificar y de detallar la iconografía de la desviación, la anormalidad y la monstruosidad.

\section{La deformidad física y moral en Roberto Artl}

En el conjunto de los cuentos de Roberto Artl (1900-1942) encontramos diversas figuras humanas definidas, ante todo, por su deformación física. Es el caso de "Extraordinaria historia de dos tuertos", donde un sujeto que cuenta con esta discapacidad adquiere un ojo de vidrio gracias a un benefactor que, finalmente, se revela como un espía que utilizaba la esfera para enviar mensajes al enemigo. A diferencia de "El jorobadito", es un cuento narrado por 
el ser deforme. Como cuento, es un simple juego lúdico que no comunica al lector el carácter siniestro con el que la sociedad asume muchas veces la 'deformidad' física.

A diferencia del cuento mencionado, "El jorobadito" (1933) ha acaparado el interés de la crítica literaria en numerosas ocasiones. En cualquier caso, la atención no se ha centrado en la construcción de la monstruosidad moral y física del jorobado y en la actitud de este último ante esta definición social, sino en la monstruosidad moral del narrador. Para Garrett (2010, pp. 187-197), este cuento, al mostrar como ilusoria la distinción entre los miembros sanos y los corruptos de la sociedad, ataca uno de los discursos hegemónicos durante las primeras décadas del siglo XX en Argentina, a saber, el de la higiene social, encaminado a establecer férreas fronteras entre los mencionados miembros sanos y los enfermos. El protagonista pequeñoburgués del cuento se revela, frente a sus propias pretensiones, como un ser moralmente degradado, idéntico al 'monstruo' moral, el jorobado, al que trata con desprecio. En la misma línea, Ruiz-Barrionuevo (1988, pp. 3-11), por su parte, destaca que el personaje del jorobado Rigoletto es un doble del narrador innominado: es un sujeto que le hace tomar conciencia a este último de la moral grotesca que trata de esconder, tras su pretensión de pertenencia a la moral bienpensante pequeñoburguesa. Como vemos, el jorobado es asumido como un personaje que 'acelera' el desmoronamiento de la hipócrita moral burguesa del narrador, moral que hasta el momento de conocer a este sujeto marginal sostenía el narrador de manera bastante inestable.

Sin dejar de ser correctas estas lecturas, creo que también es necesario interesarse por el propio comportamiento del personaje del jorobado. En este caso, se hace pertinente reflexionar sobre la reacción o respuesta del propio Rigoletto al lugar que la sociedad le ha asignado como jorobado, dejando en segundo plano las relaciones del innominado narrador con el sujeto marginal y la mediocre sociedad pequeñoburguesa porteña, que ha sido el eje principal de aquellos críticos literarios que, hasta el momento, se han acercado al cuento.

\section{El fracaso performativo de la voz del monstruo moral}

Como tal, el jorobado forma parte de los sujetos y los espacios marginales de los cuentos de Roberto Artl, como es el espacio de los burdeles ("Las fieras"), entre otros. En "El jorobadito", el narrador conoce por azar a Rigoletto y, con el objetivo de romper definitivamente con un noviazgo que le repudia, le propone a su novia, como prueba de amor, que bese al jorobado, con quien ha acordado previamente este plan. El narrador presupone que su novia responderá con el rompimiento del compromiso previamente establecido. En el cuento se establece una asociación 'bizarra' entre un sujeto marginal, cuya cotidianeidad gira alrededor de los bajos fondos, y un individuo burgués o pequeñoburgués. Por lo general, en las representaciones literarias del siglo XIX e inicios del XX, este último se acerca a la Otredad deforme con un interés instrumental, utilitario. Esta relación interclasista fue abundantemente cultivada en la literatura occidental en el Romanticismo, el Decadentismo y el Naturalismo, y fue un motivo tratado por Mario Praz en La carne, la muerte y el diablo en la literatura romántica (1999 [1930]). Compañeros de correrías criminales, sexuales o de otro tipo por los bajos fondos, esta asociación 'antinatural', según las reglas burguesas, termina violentamente por regla general.

Tres de las modalidades de relación de la sociedad con el sujeto físicamente deforme se aprecian en el trato del narrador con el jorobado. En primer lugar, la ausencia de la Belleza canónica en Rigoletto le provoca repugnancia al narrador. Como consecuencia, escarnece 
al jorobado mediante el insulto: es un sujeto ridículo sobre el que se ejerce el sadismo del sujeto pequeñoburgués resentido. No ahorra términos para designarle despreciativamente: ‘jorobadito', 'sapo', ‘bufón', ‘bufoncillo', 'parásito', 'contrahecho', 'cojo', 'giboso', 'corcovado', incluso el propio nombre de 'Rigoletto' (que el personaje del jorobado considera ofensivo...). El diminutivo ‘jorobadito’ cumple una función descalificadora y, al mismo tiempo, tranquilizadora: el narrador anula parcialmente la repulsión y el temor que proyecta sobre Rigolleto mediante el rebajamiento de su humanidad.

En segundo lugar, en el cuento de Artl también aparece una alusión a la representación cultural del jorobado como sujeto que atrae la buena suerte: es un atributo del imaginario social que Rigoletto se encarga de desmentir burlonamente. El narrador le da dos palmadas en la giba al jorobado, como señal de amistad, simple indicio de cordialidad ante un sujeto que acaba de conocer, acción con la que responde irónicamente el jorobado, consciente de la superstición pública que rodea a la giba: "-iQue le aproveche, caballero, porque a mí no me ha dado ninguna suerte!"” (p. 16). ${ }^{1}$

En tercer lugar, el narrador simboliza la ideología represora de la sociedad hegemónica al etiquetar moralmente la deformidad física. En consecuencia, tipifica a Rigoletto desde la monstruosidad moral: "todos los contrahechos son seres perversos, endemoniados, protervos" (p. 9). La crítica ha descuidado el hecho de que la descripción del jorobado realizada por el narrador responde al modelo del retrato frenológico, en boga en el siglo XIX y las primeras décadas del XX, un buen procedimiento para sugerir al lector -por parte del narrador- la potencial predisposición a la criminalidad de Rigoletto: "lo que causaba en él un efecto extraño, además de la consabida corcova, era la cabeza cuadrada y la cara larga y redonda, de modo que por el cráneo parecía un mulo y por el semblante un caballo" (p. 13). Este retrato frenológico, además, va acompañado de la animalización, uno de los procedimientos típicos en la construcción de la Otredad degradada. La semejanza del rostro de Rigoletto con la cabeza de un caballo nos recuerda la animalización que el narrador del cuento El hombre que parecía un caballo, de Rafael Arévalo Martínez, somete al personaje del señor de Aretal.

El enano jorobado representa para el narrador lo que Michel Foucault define como monstruo moral. En primer lugar, lo caracteriza como un individuo cruel, sádico, que azota a una cerca sin ningún motivo. El narrador precisa que "descargaba latigazos en el crinudo lomo de la bestia, rechinando los dientes como un demonio de teatro" (p. 10). La sexualidad lujuriosa es otro rasgo monstruoso que Occidente le ha asignado al jorobado -así sucede también en la representación que el narrador se hace de Rigoletto-, muchas veces vinculado al desparpajo o el descaro en la conducta y el discurso. Este descaro ya caracteriza al jorobado desde el preciso momento en el que el narrador cobra un primer contacto visual con él: el jorobado "observábame con toda atención, sentado del modo más indecoroso del mundo, pues había puesto la silla al revés y apoyaba sus brazos en el respaldo de ésta" (p. 13). La insolencia, es decir, la ausencia de censura moral en el discurso, es un atributo que acompaña a la figura del bufón, que muchas veces ha sido, además, un sujeto jorobado. Pavis (1998, p. 58) nos recuerda la conocida función del bufón en el teatro occidental, cuyo "estatuto de exterioridad le autoriza a comentar impunemente los acontecimientos, en una especie de forma paródica del coro trágico". La sinceridad descarada es un atributo clásico del bufón (véase Escorial, de Michel de Ghelderode, 1898-1962). El bufón jorobado más conocido en la historia cultural de Occidente estuvo al servicio de la corte del ducado de Mantua. Es, recordemos, el Rigoletto de la ópera de Giuseppe Verdi, estrenada en 1851, adaptación de la obra dramática El rey se divierte (Le 
Roi s'amuse), de Victor Hugo. El narrador llama 'bufoncillo' al jorobado, tanto por su humor insolente como por alusión al nombre que le ha otorgado al conocerle, el de 'Rigoletto'.

En la historia de la literatura occidental, ciertos sujetos marginales expresan lo que los representantes de la ideología hegemónica no se atreven a reconocer. Representa una conciencia libre de la afectación, de la hipocresía, de las normas y de las trabas sociales. ${ }^{2}$ Pero Rigoletto, en el cuento de Artl, va más lejos: no solo le muestra al narrador el mundo hipócrita en el que vive, donde el matrimonio es el único destino para el mediocre sujeto pequeñoburgués. Además, tiene capacidad para recusar o refutar las definiciones que la sociedad le ha impuesto. A diferencia de otros jorobados de la literatura occidental, es un personaje que refuta los enunciados ajenos que le rebajan. Es capaz de acusar directamente a su interlocutor, que le denigra, de ser un representante del escarnio social. Pero Rigoletto tiene un objetivo más ambicioso: pretende que la sociedad deje de percibirle como monstruo físico-moral, y pase a ser tratado como sujeto humano digno. En la escena final del cuento, Rigoletto pretende resignificar positivamente, ante la sociedad, la definición biológica-legal del jorobado como sujeto anormal: "es necesario que Elsa me dé un beso para que yo le perdone a la humanidad mi corcova. A cuenta del beso, sírvanme un té con coñac. ¡Es una vergüenza cómo ustedes atienden a las visitas! ¡No tuerza la nariz, señora, que para eso me he perfumado!” (pp. 28-29); “Ustedes están obligados a atenderme como a un caballero. El hecho de ser jorobado no los autoriza a despreciarme" (p. 29); "La novia de mi amigo está obligada a darme un beso. Y no lo rechazo. Lo acepto. Comprendo que debo aceptarlo como una reparación que me debe la sociedad, y no me niego a recibirlo" (p. 29). La sociedad se opone a sus pretensiones y recibe, como sanción, el castigo bajo la forma del asesinato, perpetrado por el narrador. ¿Por qué comete esta acción? Por haber traspasado 'Rigoletto' el umbral del comportamiento socialmente permitido a un sujeto moral y físicamente deforme. Mientras que el discurso académico y el activista han tenido un éxito parcial en la resemantización positiva del término queer frente a la sociedad hegemónica (Butler, 2002), el personaje del jorobado, en el cuento de Artl, en su contacto con la mediocre sociedad pequeñoburguesa, en sus pretensiones de revertir la definición social del ser anormal, no obtiene el éxito que pretende. Fracasa el intento de obtener, para las reivindicaciones que plantea, el efecto performativo que se propuso.

La sociedad pequeñoburguesa sanciona negativamente (es decir, castiga) todo intento de normalización emprendido por el sujeto anormal, y en este caso el intento de normalización consiste en la posibilidad de recibir un beso de una mujer. No termina asesinado por desafiar las definiciones que la sociedad le ha impuesto -ya que este desafío forma parte de la conducta descarada que ejerce cotidianamente, sin mayores consecuencias-. Préstese atención al hecho de que el narrador mata al jorobado cuando este último reivindica la legitimidad de recibir amor. Desde el presente de la enunciación, el narrador se confiesa a sí mismo que el jorobado es una simple víctima del escarnio cruel de la sociedad. La compañía cotidiana del jorobado termina por modificar -dialógicamente- su visión de los parias sociales:

\footnotetext{
si Rigoletto hubiera sido mi hermano, yo toda la vida lo hubiera compadecido con angustia enorme. Por su aislamiento, por su falta de amor que le hiciera tolerable los días colmados por los ultrajes de todas las miradas. Y me añadía que la mujer que me hubiera querido debía primero haberlo amado a él (Artl, 2003, p. 25)
}

El delito del jorobado, la legitimidad que tiene la sociedad para escarnecerlo, es carecer de los lazos familiares necesarios para que sea sujeto de respeto. La fragmentación y la alienación social lo convierten en una monstruosidad temida y escarnecida. 


\section{Conclusiones}

Las representaciones del jorobado como monstruo moral quedan reglamentadas en el siglo XIX. Mientras la jorobada -casi siempre una niña, una 'jorobadita'- es objeto de conmiseración por su 'deformidad física', el jorobado, por el contrario, queda revestido de atributos siniestros. Es un personaje secundario de los ambientes delictivos y criminales de las novelas románticas, realistas, decadentistas y naturalistas. Antes del siglo XX, materializa la estética de lo grotesco. En la literatura del siglo XX, en cambio, ya contamos con personajes jorobados que, con voz propia, desafían las etiquetas morales de la sociedad hegemónica.

Rigoletto, en particular, desafía las definiciones de la sociedad hegemónica sobre los jorobados y le demuestra al narrador protagonista la mala fe que incorporan. Su discurso es una respuesta implícita al discurso ajeno (moral, jurídico, etc.). Pero Rigoletto no solo 'destapa' el engaño de las definiciones normativas. También pretende que la sociedad modifique su comportamiento frente a la 'deformidad física y moral': es decir, pretende que la resignificación positiva que, según este personaje, debe tener el término 'jorobado', se encuentre acompañada, asimismo, de una modificación de las conductas sociales. Por este motivo, contra el deseo de la novia del narrador, reivindica la legitimidad de besarla: considera que él también tiene derecho de ser objeto de amor y de deseo. La fuerza performativa de sus palabras es nula, en una sociedad que atribuye inmoralidad a la 'ausencia de proporción física' en el cuerpo humano. La sociedad termina por sancionar negativamente, por castigar, su osadía: es asesinado por el narrador, a pesar de sus planes iniciales de provocar este beso y romper con su relación. Rigoletto, en la Argentina de las primeras décadas del siglo XX, no pudo legitimar su visión de mundo (el lugar deseable que debería ocupar un sujeto 'jorobado' en la sociedad): no estaban dadas las condiciones sociales para que su discurso lograse modificar las relaciones de los demás, mediante la empatía y la identificiación, con su propia dignidad y 'humanidad'.

\section{Notas}

1. A partir de este momento, toda cita del cuento pertenece a la siguiente edición: Artl, Roberto. 2003. "El jorobadito". En: El jorobadito y otros cuentos. Córdoba, Argentina: Ediciones del Sur.

2. La crítica descarada de la hipocresía social se hace evidente en los eufemismos que, según Rigoletto, otorgan los trabajadores a sus oficios: el lustrador de botas se exhibe como profesional del betún, el remendón de calzado como técnico del calzado.

\section{Bibliografía}

Arévalo-Martínez, R. (1958). Nuestra Señora de los Locos. El Hombre que Parecía un Caballo y Otros Cuentos. (111-38). San Salvador: Departamento Editorial del Ministerio de Cultura.

Aristóteles. (1994). Poética. Barcelona: Editorial Icaria.

Artl, R. (2003a). El jorobadito. El jorobadito y otros cuentos. (8-29). Córdoba: Ediciones del Sur.

Artl, R. (2003b). Las fieras. El jorobadito y otros cuentos. (30-46). Córdoba: Ediciones del Sur.

Burke, E. (1987). Indagaciones filosóficas sobre el origen de nuestras ideas acerca de lo sublime y de lo bello. Madrid: Tecnos. 
Butler, J. (2002). Críticamente subvesiva. Por R. M. Mérida-Jiménez (Ed.). Sexualidades transgresoras. Una antología de estudios queer. (55-79). Barcelona: Editorial Icaria.

Foucault, M. (2000). Los anormales. México: Fondo de Cultura Económica.

Garrett, V. L. (2010). Dispelling Purity Myths and Debunking Hygienic Discourse in Roberto Arlt's 'El jorobadito'. Hispania. 93 (2), 187-197.

Hugo, V. (1980). Nuestra Señora de París. Madrid: Alianza editorial.

Hugo, V. (2001). Prólogo al 'Cromwell'. Manifiesto romántico. Escritos de batalla. Barcelona: Ediciones Península.

Pardo-Bazán, E. (1999). El cisne de Vilamorta. Obras completas. Tomo I. Novelas. (641-826). Madrid: Fundación José Antonio de Castro.

Pavis, P. (1998). Diccionario del teatro. Barcelona: Editorial Paidós.

Peña, M. (2004). Juan Ruiz de Alarcón: biografía y comedias. Por I. Arellano (Coord.). Paraninfos, segundones y epígonos de la comedia del Siglo de Oro. (61-68). Barcelona: Editorial Anthropos.

Pérez-Galdós, B. (1993). Novelas, VI. Fortunata y Jacinta. Madrid: Turner Libros.

Praz, M. (1999 [1930]). La carne, la muerte y el diablo en la literatura romántica. Barcelona: El Acantilado.

Quevedo, F. de. (1852). Sátira de Quevedo contra Ruíz de Alcarcón. Por J. E. Hartzenbusch (Il. y Comp.). Biblioteca de Autores Españoles, desde la formación del lenguaje hasta nuestros días. Comedias de Don Juan Ruíz de Alarcón y Mendoza. Colección hecha e ilustrada por don Juan Eugenio. (Tomo 20). (xxxi-xxxii). Madrid: Imprenta e estereotípia de M. Rivadeneyra.

Reyero, C. (2005). La belleza imperfecta. Discapacitados en la vigilia del arte moderno. Madrid: Ediciones Siruela.

Rodríguez-McGill, C. (2012). Intertextualidad, xenofobia y la construcción del imaginario del delito urbano en El jorobado y Astucia de una negra, de Eduardo Gutiérrez. Cincinnati Romance Review. 34, 112-126.

Ruiz-Barrionuevo, C. (1988). Doble y parodia en 'El jorobadito', de Roberto Artl. Hispamérica. 17 (49), 3-11.

Shakesperare, W. (1998). Ricardo III. Santiago de Chile: Editorial Andrés Bello. 
